\title{
Penerapan Metode Cooperative Integrated Reading and Composition (CIRC) dalam Peningkatan Kemampuan Siswa Memahami Teks Bahasa Arab
}

\author{
Mar'atusolikah \\ Institut Agama Islam Negeri (IAIN) Syekh Nurjati Cirebon \\ Email: maratusolikah325@gmail.com \\ Sopwan Mulyawan \\ Institut Agama Islam Negeri (IAIN) Syekh Nurjati Cirebon \\ Email: sopmulyawan@gmail.com \\ Nanin Sumiarni \\ Institut Agama Islam Negeri (IAIN) Syekh Nurjati Cirebon \\ Email: nanisumiarni@gmail.com
}

\begin{abstract}
Abstrak
Penelitian ini bertujuan untuk mengetahui sejauh mana pengaruh penerapan metode CIRC dalam meningkatkan kemampuan Siswa memahami teks bahasa Arab Kelas XMAN 2 Cirebon. Metode CIRCdari segi bahasa bisa diartikan sebagai suatu metode pembelajaran kooperatif yang mengintegrasikan suatu bacaan secara menyeluruh kemudian mengkomposisikannya menjadi bagian-bagian yang penting.Fokus utama kegiatan metode ini adalah membuat penggunaan waktu menjadi lebih efektif. Peserta didik dikondisikan dalam tim-tim kooperatif yang kemudian dikoordinasikan dengan pengajaran kelompok membaca, supaya memenuhi tujuannya seperti pemahaman membaca. Dengan begitu peserta didik termotivasi untuk saling bekerja sama dalam sebuah tim.Penelitian ini menggunakan metode kuantitatif dengan jenis metodeQuasi Experimentdan desain penelitian Nonequivalent Control Grup Design. Metode pengumpulan data dalam penelitian ini menggunakan Observasi, Wawancara dan Tes, sampelnya adalah siswa kelas 10 MAN 2 Cirebon yang terbagi menjadi dua kelas, sedangkan tekhnik pengambilan sampelnya menggunakan yaitu Cluster Random Sampling dan peneliti mengambil siswa kelas 10 IPS 5 dan siswa kelas 10 IPS 1 sebagai kelas kontrol. Penelitian ini menegaskan bahwa terdapat perbedaan yang signifikan antara hasil belajar sebelum dan sesudah penggunaan metode CIRC.
\end{abstract}

Kata Kunci: Metode Circ, Kemampuan Siswa, Keterampilan Membaca 


\section{Abstract}

This study aims to determine the extent of the influence of the use of CIRC Methods to the reading Arabian text ability of $10^{\text {th }}$ grade students in public high school 2 Cirebon. The CIRC method in terms of language can be interpreted as a cooperative learning method that integrates a reading thoroughly and then compositing it into important parts.The main focus of this method is to make the use of time more effective. Learners are conditioned in cooperative teams that are then coordinated with the teaching of reading groups, so as to fulfill their objectives such as reading comprehension. So learners are motivated to cooperate with each other in a team. This research uses quantitative methods with the type of Quasi Experiment method and the design of the Nonequivalent Control group Design Research. The method of data collection in this study using documentation, interviews and tests, the sample is a Grade $10^{\text {th }}$ students of MAN 2 Cirebon divided into two classes, while the sampling technology using the Cluster Random Sampling and researchers took the grade 10 students of IPS 5 and students of Grade 10 IPS 1 as the control class. This study confirms that there are significant differences between learning outcomes before and after the use of the CIRC method.

\section{Keywords: CIRC Method, Student Ability, Reading Skills}

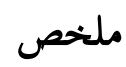

يهدف هذا البحث إلى تحديد مدى تطبيقطريقة التعليم التعاوني المتكامل في القراءة لترقية قدرة الطلاب على فهم النصوص العربية المقروءة الفصل العاشربالمدرسة الثانوية الإسلامية الحكومية 2 شربون. إن الطريقة التعليمية هي كيفية لنقل العلوم إلى الدارس التّى يستخدمها لترهيا المدرس في عملية التعلم والتعليم، ولذلك لابد على المدرس أن يطبّق الطريقة المناسبة بالمادة وتؤثر على نجاح الطلاب في التعلم.طريقة التعليم التعاوني المتكامل هي طريقة صحيحة لترقية قدرة الطلاب على فهم النصوص العربية. وهذه الطريقة هي طريقة فعالة في تعليم اللغة العربية

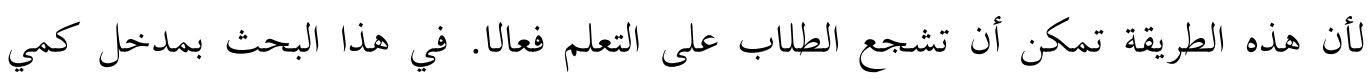
ونوعه quasi experiment وتصميم البحث Nonequivalent Control Grup Design. طريقة جمع البيانات في هذا البحث هي الملاحظة والمقابلةو الاختبار. وطريقة تحليل البيانات

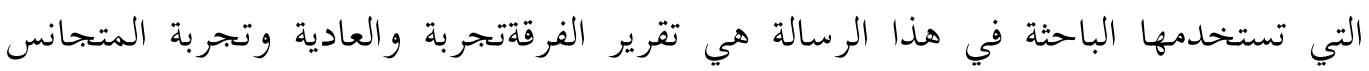




\section{وتجربة الفروض.ومن نتائج هذه الرسالة أن تعليم مهارة القراءةبتطبيق طريقة التعليم التعاوني المتكامل تؤثر على تحقيق أهداف التدريس. \\ الكلمة الرئيسية: طريقة التعليم التعاوني المتكامل في القراءة، قدرة الطلاب، مهارة القراءة}

\section{Pendahuluan}

Metode Salah satu perkembangan bahasa yang penting bagi peserta didik adalah ketrampilan membaca. Membaca merupakan sebuah keterampilan utama yang harus dimiliki oleh siswa, dengan membaca siswa dapat mengenal dan menambah pengetahuan dengan mudah. Membaca memiliki nilai yang sangat strategis dalam Pengembangan diri. ${ }^{1}$

Membaca merupakan aktivitas audio visual untuk memperoleh makna dari simbol berupa huruf atau kata. Membaca dibagi menjadi dua tahap,yaitu membaca permulaan dan membaca pemahaman. Pembedaan pembelajaran tersebut dilaksanakan sesuaidengan kelasawal (pelajaran membaca permulaan), dan kelas tinggi (pelajaran membaca lanjut atau pemahaman).

Membaca pemahaman merupakan ketrampilan membaca secara kognitif (membaca untuk memahami). Oleh karena itu setelah siswa membaca teks bacaan selanjutnya diminta untuk menyampaikan hasil pemahaman membacanya dengan cara membuat rangkuman isi bacaan dengan menggunakan bahasa sendiri dan menyampaikannya baik secara lisan maupun tulisan. Membaca permulaan mencakup pengenalan bentuk huruf, pengenalan hubungan atau korespondensi pola ejaan dan bunyi (kemampuan menyuarakan tulisan), dan kecepatan membaca bertaraf lambat. ${ }^{2}$

Kemampuan membaca yangdiperolehpadamembacapermulaan akan sangat berpengaruh terhadap kemampuan membaca lanjut. Jika pada membaca permulaan belum kuat,maka pada tahap membaca lanjut siswa akan mengalami kesulitan untuk dapat memiliki kemampuan yang

${ }^{1}$ Priyudari, Tastra, dan Suartama, "Pengaruh Metode Pembelajran Tipe Silent Way Berbantu Multimedia Pembelajaran Interaktif Kelas XI Jurusan Bahasa Semester Genap," dalam E-Journal Edutech, (2015). Hal. 48.

2 Retnaningrum, Primastuti, dan Utami, "Pembelajaran Kesadaran Fonemik dengan Menggunakan Metode SAS untuk Meningkatkan Kemampuan Membaca Permulaan Siswa Kelas Satu Sekolah Dasar," dalam Prediksi, (2015). Hal. 81-91. 
memadai. Siswa dikatakan mempunyai kemampuan membaca permulaan manakala siswa tersebut tepat dalam meyuarakan tulisan, kewajaran lafal, kewajaran intonasi, kelancaran, kejelasan suara, dan pemahaman isi/makna. ${ }^{3}$

Fakta yang terjadi dilapangan yang diperoleh dari data wawancara dengan guru bahasa Arab kelas X di Madrasah Aliyah Negeri 2 Cirebon bahwasanya banyak siswa yang masih belum mampu memahami teks bacaan dalam bahasa Arab, sehingga kemampuan membaca mereka masih termasuk dalam tingkat rendah. Darihasil observasiolehpeneliti diperoleh fakta guru belum menggunakan metode pembelajaran yang tepat sehingga cenderung membuat para siswa merasa bosan dan tidak mengikuti proses pembelajaran dengan baik. Ketika kegiatan belajar di kelas mereka terlihat kurang percaya diri, pendiam, dan pasif.

Pelajaran bahasa arab merupakan pelajaran yang dianggap sulit dan dianggap sebuah momok oleh siswa. Untuk mengatasi hal tersebut maka diperlukan suatu terobosan baru dalam proses pembelajaran bahasa, sehingga siswa lebih mudah untuk memahami materi yang disampaikan dan merasa senang untuk belajar bahasa arab. Sehingga seorang Guru dituntut untuk mampu menguasai berbagai metode dan strategi dalam proses pembelajaranya. Metode merupakan bagian komponen pengajaran yang menduduki posisi penting, selain tujuan, Guru, peserta didik, media, lingkungan, dan evaluasi." Salah satu metode yang bisa digunakan adalah metode CIRC. Pembelajaran kooperatif adalah konsep yang lebih luas meliputi semua jenis kerja kelompok termasuk bentuk-bentuk yang lebih dipimpin oleh guru atau diarahkan oleh guru. Secara umum pembelajaran kooperatif dianggap lebih diarahkan oleh guru, di mana guru menetapkan tugas dan pertanyaan-pertanyaan serta menyediakan bahan-bahan dan informasi yang dirancang untuk membantu peserta didik menyelesaikan masalah yang dimaksud. ${ }^{5}$

Penggunaan metode konvensional dirasa kurang efektif dalam pembelajaran bahasa Arab khususnya materi pengenalan huruf dirasa

${ }^{3}$ Saputra, "Upaya Meningkatkan Kemampuan Membaca Permulaan Melalui Metode SAS Siswa Kelas I," (Kebumen: 2012). Hal. 27.

4 Thoifuri, Menjadi Guru Inisiator. (Semarang: Rasail Media Group). Hal. 55.

${ }^{5}$ Suprijono, Cooperative Learning. ( Yogyakarta ;Pustaka Belajar, 2012 ). Hal. 54. 
membosankan dimana hanya guru yang menjadi objek dan sumber belajar. Sehingga siswa menjadi jenuh dan pembelajaran menjadi kurang efektif. Metode ini juga dianggap sebagai sumber kegagalan pengajaran bahasa asing. Mayoritas pembaharuan pengajaran Bahasa pada dasarnya dikembangkan untuk menentang metode ini. ${ }^{6}$

Keberhasilan pendidikan dalam sebuah lembaga pendidikan tidak hanya ditumpukan pada peserta didik saja tetapi lebih banyak pada seberapa besar guru memberikan solusi cara atau metode pembelajaran yang membuat peserta didik menikmati pelajaran itu serta membuatnya senang. Salah satu model pembelajaran yang dapat digunakan guru sebagai variasi dalam proses pembelajaran adalah model kooperatif.

Banyak jenis model pembelajaran kooperatif yang dapat diterapkan dalam pembelajaran bahasa Indonesia, tetapi model pembelajaran kooperatif yang digunakan dalam pembelajaran. Salah satunya adalah model Cooperative Integrated Reading and Composition.Cooperative Integrated Reading and Composition dalam pembelajaran menulis bertujuan untuk merancang, mengimplementasikan, dan mengevaluasi pendekatan proses menulis pada pelajaran menulis dan seni berbahasa yang akan banyak memanfaatkan kehadiran teman satu kelas. Dalam program Cooperative Integrated Reading and Composition, para peserta didik merencanakan, merevisi, dan menyunting karangan mereka dengan kolaborasi yang erat dengan teman satu tim mereka. ${ }^{7}$

Model pembelajaran Cooperative Integrated Reading and Composition adalah salah satu model kooperatif yang komprehensif untuk mengajarkan pembelajaran membaca, menulis, dan seni berbahasa $^{8}$.

Tujuan utama dari model ini adalah menggunakan tim-tim kooperatif untuk membantu peserta didik mempelajari kemampuan memahami bacaan yang dapat diaplikasikan secara luas. Peserta didik dalam model Cooperative Integrated Reading and Composition juga membuat penjelasan terhadap prediksi mengenai bagaimana masalah-masalah akan diatasi dan merangkum unsur-unsur utama dari cerita kepada satu

${ }^{6}$ Fatkhururrozi dan Mahyudin, Pembelajaran Bahasa Arab. (Jakarta: 2012). Hal. 56-67.

7 Slavin, Cooperative Learning. (Bandung: Nusa Media, 2010). Hal. 26.

8 Suprijono, Cooperative Learning (Teori dan Aplikasi PAIKEM). (Yogyakarta, Pustaka Pelajar,2019). Hal. 96. 
sama lain yang diharapkan dapat meningkatkan pemahaman dalam membaca.

Berdasarkan Latar belakang diatas maka peneliti akan mencoba meneliti terkait Penerapan Metode Pembelajaran CIRCuntuk Meningkatkan Kemampuan Siswa dalam Memahami Teks Bahasa Arab Kelas XMAN 2 Cirebon.

\section{Metode Penelitian}

Metode penelitian yang digunakan dalam penelitian ini adalah penelitian quasiexperiment dengan bentuk desain Nonequivalent Control Grup Design. Sampelnya adalah siswa kelas X MAN 2 Cirebon, tekhnik pengambilan sampelnya menggunakan cluster random sampling dan peneliti mengambil siswa kelas X IPS 5 sebagai kelas eksperimen dan kelas X IPS 1 sebagai kelas control. Adapun tekhnik pengumpulan data yang digunakan oleh peneliti adalah observasi, wawancara dan tes, dan peneliti menggunakan $t$-test Independent untuk mengetahui Ho.

Sumber data adalah subjek asal data penelitian itu diperoleh. ${ }^{9}$ Dalam penelitian ini peneliti menggunakan sumber data primer. Data primer yang diperoleh peneliti secara langsung dari sumber asli (tidak melalui perantara), yaitu guru Bahasa Arab dan siswa kelas X MAN 2 Cirebon.

Populasi adalah wilayah generalisasi yang terdiri atas: Obyek/subyek yang mempunyai kualitas dan karakteristik tertentu yang ditetapkan oleh peneliti untuk dipelajari dan kemudian ditarik kesimpulannya. Adapun populasi dalam penelitian ini mencakup seluruh siswa kelas X MAN 2 Cirebon yang berjumlah 282.

Sample adalah bagian dari jumlah dan karakteristik yang dimiliki oleh populasi tersebut. Apa yang dipelajari dari sample itu, kesimpulannya akan dapat diberlakukan untuk populasi (Sugiyono, 2010). Adapun teknik penarikan sample pada penelitian ini menggunakan teknik sampling probabilistik, yang dilakukan dengan cara peneliti menyeleksi individu-individu dari populasi tersebut. Jumlah sample yang akan diambil dalam penelitian ini berjumlah 31 siswa, dengan rincian 12 siswa laki-laki dan 19 siswa perempuan.

Dalam penelitian ini, peneliti menggunakan teknik pengumpulan menggunakan dokumentasi, wawancara dan tes. Tes dalam penelitian ini

\footnotetext{
${ }^{9}$ Sujarweni, Metodologi Penelitian. (Yogyakarta: Pustaka Baru Press, 2014). Hal.
} 
digunakan untuk mengukur kemampuan membaca bahasa Arab siswa setelah menggunakan metode CIRC pada pembelajaran. Adapun tes yang digunakan adalah tes lisan dan tulis.

Untuk lebih jelas, teknik pengumpulan data secara lengkap dapat dilihat pada tabel berikut:

\begin{tabular}{|l|l|l|l|}
\hline \multicolumn{1}{|c|}{ Data } & \multicolumn{1}{c|}{$\begin{array}{c}\text { Sumber } \\
\text { Data }\end{array}$} & \multicolumn{1}{|c|}{ Instrumen } & Keterangan \\
\hline $\begin{array}{l}\text { Tes } \\
\text { kemampuan } \\
\text { membaca }\end{array}$ & Siswa & $\begin{array}{l}\text { Tes lisan dan } \\
\text { tulis }\end{array}$ & $\begin{array}{l}\text { Sesudah } \\
\text { pembelajaran }\end{array}$ \\
\hline
\end{tabular}

Dalam uji validitas, peneliti menggunakan uji validasi yang dilakukan oleh tim ahli.

Reliabilitas suatu tes merupakan derajat ketetapan dalam mendapatkan data yang diberikan pada kesempatan berbeda atau tes paralel pada waktu yang sama. Reliabilitas alat penilaian adalah ketetapan atau keajegan alat dalam menilai apa yang dinilainya. Peneliti menggunakan rumus product moment dengan cara belah awal akhir dengan rumus:

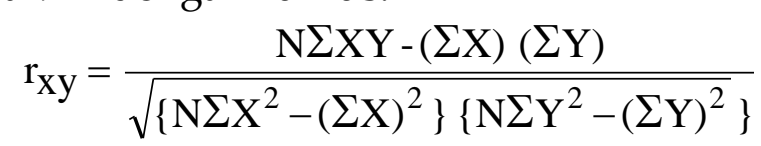

Selanjutnya menlgyundakan rumlus spedrindı drown (Riduwan, 2012) berikut:

$$
\mathrm{r} 11=\frac{2, r b}{(1+r b)}
$$

Keterangan:

r11 = Koefisien reliabilitas

$\mathrm{rb}=$ Korelasi Product Momen antara belahan (ganjil-genap)

Uji normalitas bertujuan untuk mengetahui apakah data berdistribusi normal atau tidak. Dalam hal ini, peneliti menggukan statistik uji chi kuadrat dengan rumus sebagai berikut:

$$
x^{2}=\sum_{i=1}^{k} \frac{(O i-E i)^{2}}{E i}
$$

Keterangan:

$\mathrm{X}^{2}$ : chi kuadrat

Oi : frekuensi yang diobservasi

Ei : frekuensi yang diharapkan 
Selantujnya dari $\chi 2$ hitung yang telah diperoleh dibandingkan dengan $\chi 2$ tabel dengan derajat kebebasan $\mathrm{dk}=\mathrm{K}-3$ dan taraf signifikansi $\alpha=5 \%$. Data dikatakan normal apabila $\chi 2$ hitung $<\chi 2$ tabel. ${ }^{10}$

Uji Paired Sample T Test adalah pengujian yang digunakan untuk membandingkan selisih dua mean dari dua sampel yang berpasangan dengan asumsi data berdistribusi normal. Sample berpasangan berasal dari subjek yang sama, setiap variabel diambil saat situasi dan keadaan yang berbeda. Uji ini juga disebut uji $\mathrm{T}$ berpasangan.

\section{Keterampilan Membaca}

Pada dasarnya belajar bahasa adalah belajar komunikasi. Dalam hal ini, belajar bahasa menkankan pada 4 aspek, yaitu menyimak, berbicara, membaca dan menulis. Membaca adalah jendela dunia, pepatah ini menjadi sebuah kalimat yang sangat popular di kalangan masyarakat. Dengan membaca, seseorang akan mengalami fase dimana tidak tahu menjadi tahu, tidak paham menjadi paham dan tidak pernah menjadi lebih memahami. Seseorang mampu membaca bukan karena kebetulan saja, akan tetapi karena seseorang tersebut belajar dan berlatih membaca teks yang terdiri dari kumpulan huruf-huruf yang bermakna. Di dalam kegiatan membaca, yang kita baca adalah lambing atau tanda atau tulisan yang bermakna. Dalam hal ini, lambing atau tanda atau tulisan tersebut dapat berupa kumpulan huruf yang meambentuk kata, kumpulan kata yang membentuk kalimat, kumpulan kalimat yang membentuk paragraph dan kumpulan paragraph yang membentuk wacana yang utuh. Membaca dapat pula dikatakan sebagai suatu proses dalam memperoleh informasi dengan menggunakan tekhnik membaca yang sesuai dengan tujuan membaca.

Membaca adalah suatu proses yang dilakukan serta dipergunakan oleh pembaca untuk memperoleh pesan yang hendak disampaikan oleh penulis melalui media kata-kata atau bahasa tulis. ${ }^{11}$ Dengan demikian membaca merupakan kegiatan yang penting bagi seseorang yang ingin meningkatkan diri untuk memperluas wawasannya dan mampu memhami isi dari bacaan tersebut.

10 Arikunto, Prosedur Penelitian Suatu Pendekatan Praktek. (Yogyakarta: Rineka Cipta, 2010). Hal. 67.

11 Tarigan, Menulis sebagai Suatu Keterampi Bahasa. (Bandung: Angkasa, 1983). Hal. 7. 
Salah satu perkembangan bahasa yang penting bagi peserta didik adalah ketrampilan membaca. Membaca merupakan sebuah keterampilan utama yang harus dimiliki oleh siswa, dengan membaca siswa dapat mengenal dan menambah pengetahuan dengan mudah. Membaca memiliki nilai yang sangat strategis dalam Pengembangan diri. $^{12}$

Membaca pemahaman merupakan ketrampilan membaca secara kognitif (membaca untuk memahami). Oleh karena itu setelah siswa membaca teks bacaan selanjutnya diminta untuk menyampaikan hasil pemahaman membacanya dengan cara membuat rangkuman isi bacaan dengan menggunakan bahasa sendiri dan menyampaikannya baik secara lisan maupun tulisan. Membaca permulaan mencakup pengenalan bentuk huruf, pengenalan hubungan atau korespondensi pola ejaan dan bunyi (kemampuan menyuarakan tulisan), dan kecepatan membaca bertaraf lambat. ${ }^{13}$

Membaca adalah suatu proses yang dilakukan serta dipergunakan oleh pembaca untuk memperoleh pesan, yang hendak disampaikan oleh penulis memlalui kata-kata atau bahasa tulis. Suatu proses yang menuntut agar kelompok kata yang merupakan suatu kesatuan akan terlihat dalam suatu pandangan sekilas dan makna-makna secara individual akan dapat diketahui.

Pembelajaran membaca permulaan merupakan tingkatan proses pembelajaran bahasa untuk menguasai sistem tulisan sebagai representasi bahasa. Tingkatan ini sering disebut dengan tingkatan belajar membaca, learningtoread. Sedangkan membaca lanjut merupakan tingkatan proses penguasaan membaca untuk memperoleh isi pesan yang terkandung dalam tulisan. Tingkatan ini disebut sebagai membaca untuk belajar, reading to learn. ${ }^{14}$

\section{Metode CIRC}

12 Priyudari, Tastra, dan Suartama, Pengaruh Metode Pembelajran Tipe Silent Way Berbantu Multimedia Pembelajaran Interaktif Kelas XI Jurusan Bahasa Semester Genap, dalam E-Journal Edutech, (2015), Hal. 48-58.

${ }^{13}$ Retnaningrum, Primastuti, dan Utami, Pembelajaran Kesadaran Fonemik dengan Menggunakan Metode SAS untuk Meningkatkan Kemampuan Membaca Permulaan Siswa Kelas Satu Sekolah Dasar, dalam Prediksi, (2015). Hal. 81-91.

${ }^{14}$ Dahniar, Peningkatan Keterampilan Membaca Lanjutan dengan Metode SAS siswa kelas II, dalam Kreatif Tadulaki Online, (2014). Hal. 136-138. 
Metode Cooperative Integrated Reading and Compositian adalah salah satu metode pembelajaran cooperative learning yang pada mulanya merupakan pengajaran kooperatif terpadu membaca dan menulis yaitu sebuah program komprehensif atau luas dan lengkap untuk pengajaran membaca dan menulis untuk kelas-kelas tinggi sekolah dasar. Fokus utama kegiatan Cooperative Integrated Reading and Composition adalah membuat penggunaan waktu menjadi lebih efektif. Peserta didik dikondisikan dalam tim-tim kooperatif yang kemudian dikoordinasikan dengan pengajaran kelompok membaca, supaya memenuhi tujuan lain seperti pemahaman membaca, kosa kata, pembacaan pesan, dan ejaan. Dengan begitu peserta didik termotivasi untuk saling bekerja sama dalam sebuah tim. ${ }^{15}$

Pembelajaran kooperatif adalah konsep yang lebih luas meliputi semua jenis kerja kelompok termasuk bentuk-bentuk yang lebih dipimpin oleh guru atau diarahkan oleh guru. Secara umum pembelajaran kooperatif dianggap lebih diarahkan oleh guru, di mana guru menetapkan tugas dan pertanyaan-pertanyaan serta menyediakan bahan-bahan dan informasi yang dirancang untuk membantu peserta didik menyelesaikan masalah yang dimaksud. ${ }^{16}$

\section{Penerapan Metode CIRCUntuk Meningkatkan Kemampuan Membaca}

Pada tes ini dimulai dengan memberikan pretest di kelas kontrol. Waktu yang diberikan kepada siswa sekitar 45 menit. Setelah dilaksanakan pretest, peneliti melaksanakan pembelajaran bahasa arab tanpa menggunakan metode $C I R C$. Setelah pembelajaran selesai dan untuk mengetahui kemampuan pemahaman siswa peneliti melakukan posttest untuk mengetahui perbedaan kemampuan pemahaman siswa sebelum dan sesudah pembelajaran tanpa menggunakan metode CIRC. Adapun hasilnya sebagai berikut:

Hasil tes bisa dilihat pada tabel berikut:

Statistics

\begin{tabular}{|ll|r|r|}
\hline & Pre testKontrol & Post testkontrol \\
\hline N & Valid & 23 & 23 \\
Mean & 1 & 1 & 1 \\
& & 49,19 & 71,00
\end{tabular}

${ }^{15}$ Slavin, Cooperative Learning. (Bandung: Nusa Media, 2010). Hal. 200.

16 Suprijono, Cooperative Learning: Teori dan Aplikasi PAIKEM. (Yogyakarta: Pustaka Belajar. Hal. 54-55. 


\begin{tabular}{|l|r|r|} 
Median & 45,00 & 73,00 \\
Mode & 45 & 77 \\
Minimum & 23 & 45 \\
Maximum & 73 & 91 \\
Sum & 1574 & 2272 \\
\hline
\end{tabular}

Diketahui hasil perhitingan SPSS 21 dari nilai pretest di kelas kontrol yaitu dengan nilai minimum 23, maksimum 73, median 45.00 dengan rata-rata 49,19 . Sedangkan dari nilai posttestdi kelas control yaitu dengan nilai minimum 45, maksimum 91, median 72.00 dengan rata-rata 71,00 .

Pada tes ini dimulai dengan memberikan pretest di kelas Eksperimental. Waktu yang diberikan kepada siswa sekitar 45 menit. Setelah dilaksanakan pretest, peneliti melaksanakan pembelajaran kosakata bahasa arab dengan menggunakan media gambar dan metode index card match. Setelah pembelajaran selesai dan untuk mengetahui kemampuan pemahaman siswa peneliti melakukan posttest untuk mengetahui perbedaan kemampuan pemahaman siswa sebelum dan sesudah pembelajaran dengan menggunakan metode CIRC. Adapun hasilnya sebagai berikut:

\section{Statistics}

\begin{tabular}{|c|c|c|c|}
\hline & & Pre testEksperimental & $\begin{array}{c}\text { Post } \\
\text { testEksperimental }\end{array}$ \\
\hline \multirow{2}{*}{$\mathrm{N}$} & Valid & 23 & 23 \\
\hline & Missing & 0 & 0 \\
\hline \multicolumn{2}{|c|}{ Mean } & 51,93 & 85,00 \\
\hline \multicolumn{2}{|c|}{ Median } & 50.00 & 86.00 \\
\hline \multicolumn{2}{|c|}{ Mode } & 45 & 86 \\
\hline \multicolumn{2}{|c|}{ Minimum } & 36 & 55 \\
\hline \multicolumn{2}{|c|}{ Maximum } & 73 & 95 \\
\hline \multicolumn{2}{|c|}{ Sum } & 1714 & 2805 \\
\hline
\end{tabular}

Diketahui hasil perhitungan SPSS 21 dari nilai pretest di kelas eksperimen yaitu dengan nilai minimum 36, maksimum 73, median 50.00 dengan rata-rata451,93.Sedangkan dari nilai posttest di kelas 
kontrol yaitu dengan nilai minimum 55, maksimum 95, median 86.00 dengan rata-rata 85,00.

\section{Uji Normalitas}

Uji normalitas berguna untuk mengetahui setiap sampel yang akan digunakan berasal dari populasi yang terdistribusi normal atau tidak normal. Uji normalitas data pada penelitian ini dilakukan dengan menggunakan program pengolahan data SPSS 21 melalui uji normalitas Kolmogorov-Smirnov dengan kriteria jika signifikansi $>0,05$ maka data berdistribusi normal, dan jika signifikansi $<0,05$ maka data berdistribusi tidak normal. Adapun hasil uji normalitas pada penelitian ini sebagai berikut:

Tests of Normality

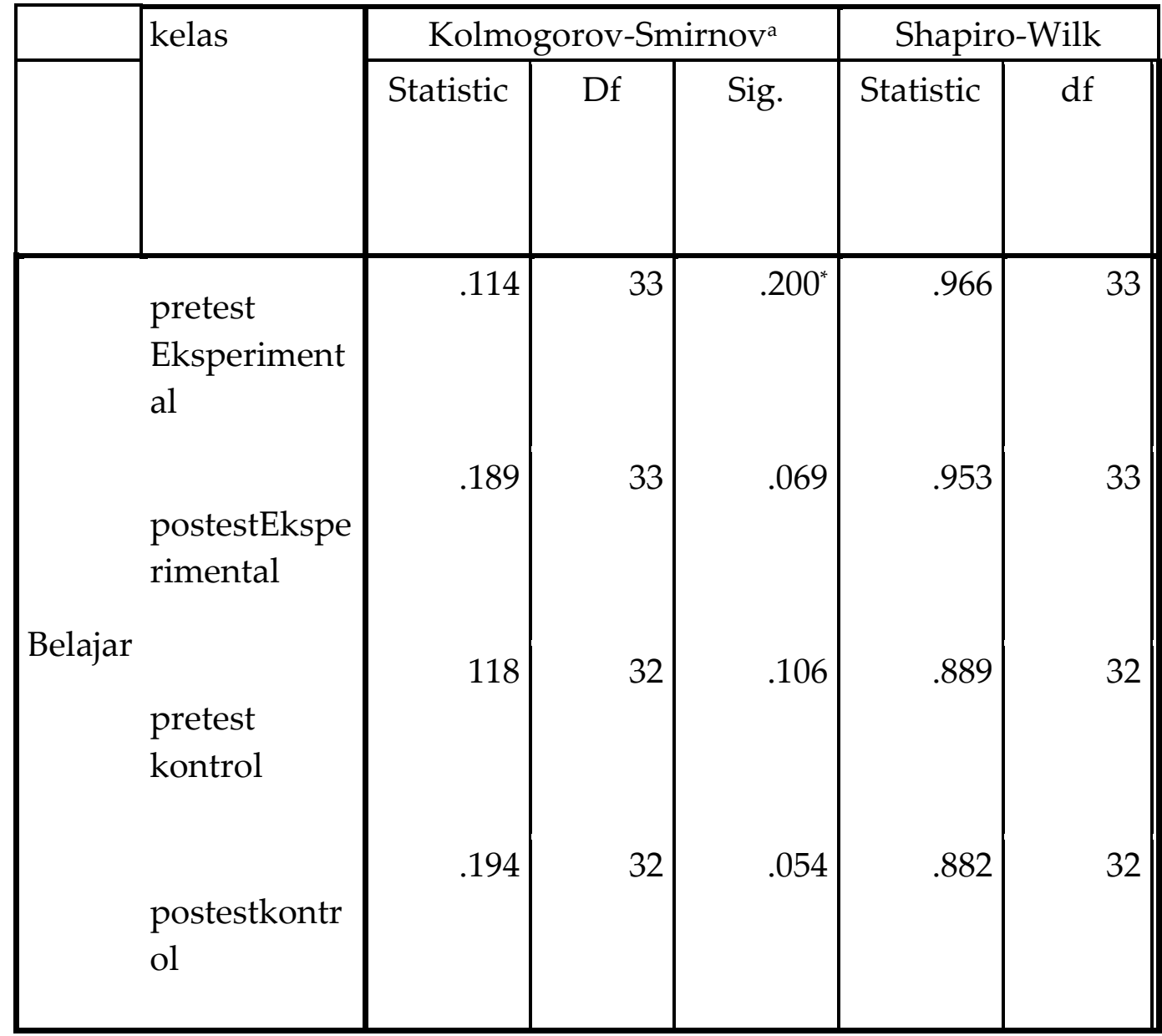

Dari tabel di atas diketahui bahwa uji normalitas di kelas control pretest-posttest dan kelas ekperimen pretest-postest sebesar $(0,57>0,05)$ dan $(0,73>0,05)$. Hal ini dapat diketahui bahwa uji nomalitas berdistribusi normal. 


\section{Uji Homogenitas}

Uji homogenitas dilakukan pada hasil data pretest dan posttest santri. Pada penelitian ini, uji homogenitas dilakukan dengan menggunakan program pengolahan data SPSS 21 melalui Levene. Kriteria pengujiannya adalah apabila nilai signifikansi atau probabilitas < 0,05 maka data tidak homogen, sedangkan jika nilai signifikansi atau nilai probabilitas $>0,05$ maka data homogen.

\section{Test of Homogeneity of Variances}

Hasil belajar kelas

\begin{tabular}{|r|r|r|r|}
\hline \multicolumn{1}{|c|}{ Levene Statistic } & \multicolumn{1}{c|}{ df1 } & df2 & \multicolumn{1}{c|}{ Sig. } \\
\hline .008 & 1 & 36 & .931 \\
\hline
\end{tabular}

\section{ANOVA}

Hasil belajar kelas

\begin{tabular}{|l|r|r|r|r|r|}
\hline & \multicolumn{1}{|c|}{$\begin{array}{c}\text { Sum of } \\
\text { Squares }\end{array}$} & \multicolumn{1}{|c|}{ Df } & Mean Square & F & Sig. \\
\hline $\begin{array}{l}\text { Between } \\
\text { Groups } \\
\text { Within } \\
\text { Groups } \\
\text { Total }\end{array}$ & 950.000 & 1 & 950.000 & 10.819 & .000 \\
\hline
\end{tabular}

Dari tabel diatas diketahui bahwa uji Homogenitas dikelas kontrol dan kelas Eksperimental sebesar 0,931>0,05. Hal ini berarti dapat kita ketahui data berdistribusi Homogen.

\section{Uji hipotesis}

Uji Hipotesis pada penelitian ini menggunakan teknik t-test. Teknik ini merupakan teknik statistik yang dipergunakan untuk menguji signifikansi perbedaan dua buah mean yang berasal dari dua buah distribusi.

Paired Samples Test

\begin{tabular}{|l|l|l|l|}
\hline Paired Differences & T & Df & Sig. \\
\hline
\end{tabular}




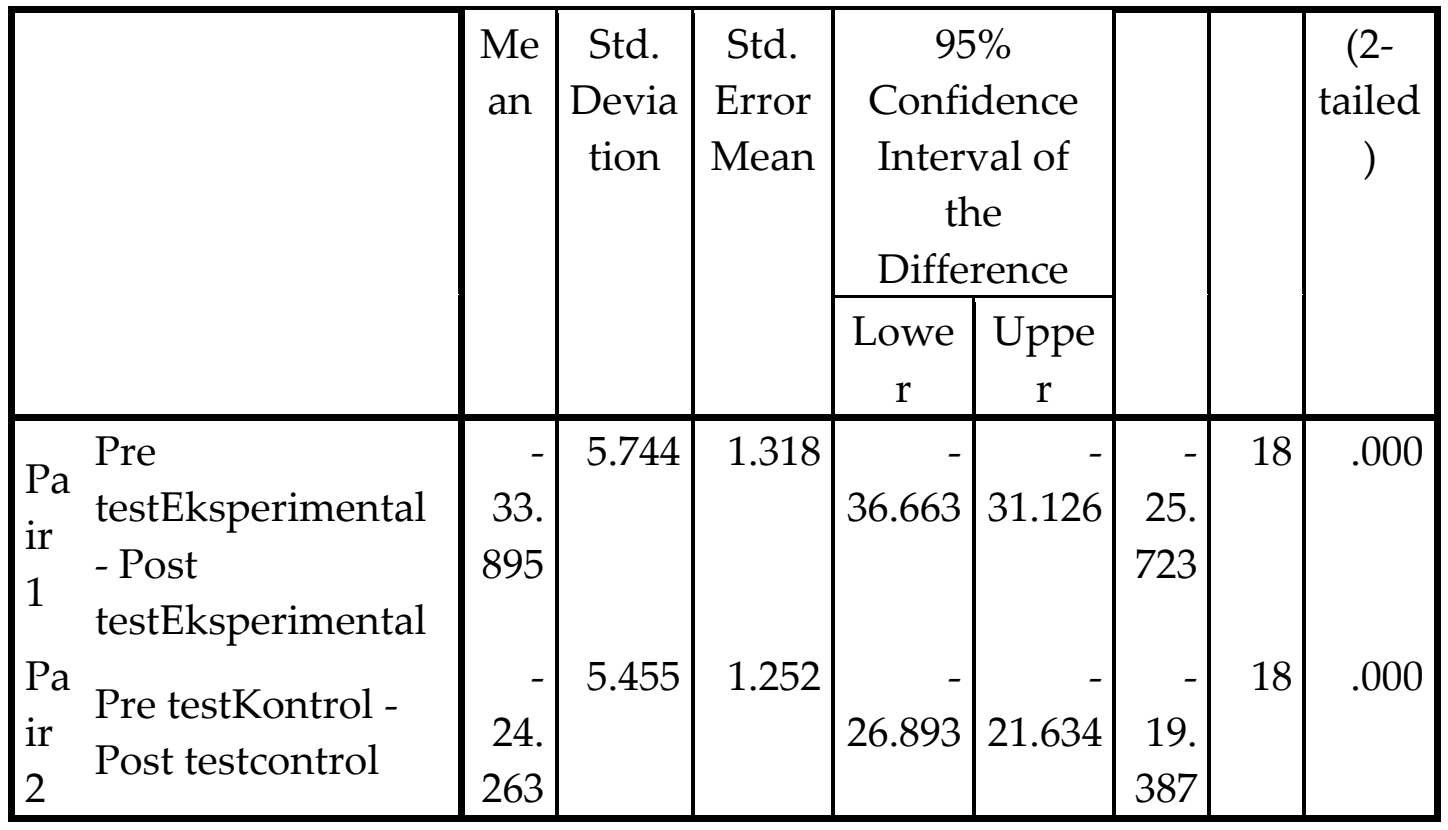

\section{Kesimpulan}

Kemampuan siswa terhadap kemampuan membaca tanpa menggunakan metode CIRC di kelas kontrol pada nilai pretest yaitu dengan nilai minimum 23, maksimum 72, median 45.00 dengan rata-rata 51,00 . Sedangkan dari nilai posttest di kelas control yaitu dengan nilai minimum 45, maksimum 91, median 73.00 dengan rata-rata 72,00. Dan keterampilan siswa terhadap kemampuan membaca dengan menggunakan metode CIRC di kelas Eksperimental pada nilai pretest yaitu dengan nilai minimum 36, maksimum 73, median 50.00 dengan rata-rata 53,00. Sedangkan dari nilai posttest di kelas Eksperimental yaitu dengan nilai minimum 55, maksimum 95, median 86.00 dengan rata-rata 85,00 . Hal ini berarti terdapat peningkatan yang besar pada hasil pretest dan posttest.

Terdapat pengaruh yang signifikan dari pemberian perlakuan terhadap kemampuan siswa dalam membaca teks bahasa Arab dengan menggunakan metode CIRC. Hal ini dibuktikan dari perhitungan T-Test dengan menggunakan analisis SPSS 21. Hasil yang diperoleh dari perhitungan tersebut adalah nilai Sig. (2 tailed) sebesar 0,000. Hasil sig. (2 tailed) sebesar 0,000 yang berarti bahwa nilai ini lebih kecil dari 0,05 dimana dapat disimpulkan bahwa Ha diterima dan Ho ditolak. 


\section{Daftar Pustaka}

Arikunto, S. 2010. Prosedur Penelitian Suatu Pendekatan Praktek. Yogyakarta: Rineka Cipta.

Dahniar. 2014. Peningkatan Keterampilan Membaca Lanjutan Dengan Metode Sas Siswa Kelas II SDN 2 Ogowele, dalam Kreatif Tadulako Online, $4(8)$.

Fakhururrozi, A., \& Mahyudin, E. 2012. Pembelajaran Bahasa Aarab (2nd ed.). Jakarta: Direktorat Jendral Pendidikan Islam Kementrian Agama.

Priyudari, B. A. P., Tastra, I. D. K., \& Suartama, K. 2015. Pengaruh Metode Pembelajaran Tipe Silent Way Berbantuan Multimedia Pembelajaran Interaktif Kelas XI Jurusan Bahasa Semester Genap, dalam E-Journal Edutech, 05(01).

Retnaningrum, S. D., Primastuti, E., \& Utami, C. T. 2015. Pembelajaran Kesadaran Fonemik Dengan Menggunakan Metode Struktural Analisis Sintesis (SAS) Untuk Meningkatkan Kemampuan Membaca Permulaan Siswa Kelas Satu Sekolah Dasar, dalam Prediksi, 4(1).

Saputra, R. 2012. Upaya Meningkatan Kemampuan Membaca Permulaan Melalui Metode Struktural Analitik Sintetik (SAS) Siswa Kelas I Di SD Negri 1 Gebangsari Kebumen. Yogyakarta: Universitas Negri Yogyakarta.

Slavin, Robert E. 2010. Cooperative Learning (Teori, Riset, dan Praktik). Bandung: Nusa Media.

Sugiyono. 2010. Metode Penelitian Pendidikan (Pendidikan Kuantitatif, Pendekatan Kualitatif dan $R$ \& D). Bandung: Alfabeta.

Sujarweni. 2014. Metodologi Penelitian. Yogyakarta: Pustaka Baru Press.

Suprijono, Agus. 2012. Cooperative Learning: Teori dan Aplikasi Paikem. Yogyakarta: Pustaka Pelajar.

Tarigan 1981. Berbicara sebagai suatu keterampilan Berbahasa. Bandung: Angkasa.

Thoifuri. Menjadi Guru Inisiator. Semarang: Rasail Media Group. 